\title{
CORPO E GESTALT: VIDA EM MOVIMENTO
}

Maristela ROCHA *

*Mestre em Comunicação e Cultura pela UFRJ, jornalista, professora universitária. Discente do curso de Pós-Graduação em Educação Musical e Música Brasileira, UninCor. maristelarocha@yahoo.com

\section{Recebido em: 30/10/2013 - Aprovado em: 15/10/2013 - Disponibilizado em: 15/01/2014}

Resumo: O estudo do comportamento cerebral durante o processo de percepção possibilitou a elaboração de leis específicas que regem a Gestalt, teoria da psicologia desenvolvida no final do século XIX na Áustria e Alemanha. Essas leis básicas da Gestalt são usadas em várias áreas na atualidade: no design, cinema, na publicidade e propaganda, na moda e não poderia ficar de fora do estudo da prática interpretativa, da performance corporal e artística. Ganhou ênfase na pedagogia, filosofia, nas artes, e muito deverá ser investigado e revelado ainda sobre o assunto. A linguagem corporal é, muitas vezes, mais adequada do que a linguagem verbal para informar sobre as atitudes e emoções de um indivíduo. Pretendemos neste trabalho mostrar a relação entre corpo e Gestalt. Utilizaremos exemplificações que poderão ilustrar nossa explanação, além de sete vídeos ilustrativos que nos apoiam como referencial bibliográfico eletrônico. Mas será possível utilizar a Gestalt para melhorar a performance artística? Há relação entre corpo, Gestalt e performance?

Palavras-chave: Corpo. Gestalt. Comunicação. Performance. Arte.

\begin{abstract}
The study of brain behavior during the process of perception allowed the drafting of specific laws governing the Gestalt psychology theory developed in the late nineteenth century in Austria and Germany. These basic laws of Gestalt are used in many areas nowadays: in design, film, advertising, trendy and could not stay out of the study of interpretive practice, performance and body art. Won emphasis on pedagogy, philosophy, the arts, and much must be investigated and revealed yet on the subject. Body language is often more appropriate than verbal language to inform the attitudes and emotions of an individual. We intend this work to show the relationship between body and Gestalt. We will use instantiations that may illustrate our explanation, beyond seven illustrative videos that support us as electronic bibliographic references. But you can use Gestalt to improve performance art? There is a relationship between body, Gestalt and performance?
\end{abstract}

Keywords: Body. Gestalt. Communication. Performance. Art.

\section{INTRODUÇÃO}

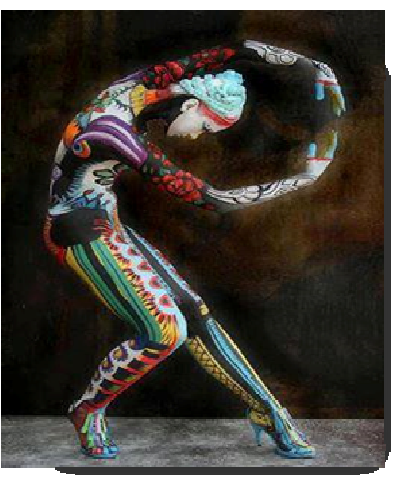

O fenômeno global do corpo é, do ponto de vista intelectual, tão superior à nossa consciência, ao nosso espírito, à nossa maneira de pensar, de sentir e de querer, quanto a álgebra é superior à tabuada de multiplicação.

*NIETZCHE
Podemos considerar o corpo a nossa primeira mídia e estender essa proposição à análise de outras áreas do conhecimento como a Gestalt? Se o estudo do corpo e as suas representações simbólicas acompanham a própria trajetória do homem na Terra, como podemos investigar este tema à luz da atualidade?

$\mathrm{O}$ século $\mathrm{XX}$ nos legou um complexo de situações que nos desestabilizam a cada momento, enfatizadas por características consideradas Pós-Modernas como a globalização, a alta tecnologia, o 
consumismo, o hedonismo, o niilismo, as crises econômicas, ambientais e sociais. Isso porque o indivíduo da contemporaneidade é essencialmente performático. Quando essa performance é abalada, as inúmeras facetas corporais são afetadas.

A sociedade, em todos os tempos, cria estereótipos da imagem corporal, moldando a estética de acordo com os padrões de beleza vigentes. Essa mesma sociedade rejeita corpos mutilados ou distantes dos valores em voga. As pessoas procuram sempre uma maneira de identificação com o outro, encaixando-se no padrão estabelecido. Essa corrida pela adaptabilidade é, muitas vezes, uma fonte de desajuste emocional e físico.

Os primeiros anos do novo século são marcados pelo limite diário entre a vida e a morte; às vezes, pela morte em plena vida. $\mathrm{O}$ corpo espetáculo, o corpo do prazer, do risco, dos extremos, a euforia propiciada por medicamentos ou drogas ilícitas apresentamse como marcantes características contemporâneas. As ciências biomédicas, cada vez mais, vêm acompanhando essa tendência.

$\mathrm{O}$ aparato tecnológico permite que possamos regrar as formas de nosso corpo, reduzindo a distância entre o que deseja a mente e o seu reflexo orgânico, através de moderadores de apetite, substâncias que permitam maior desempenho sexual, drogas para insônia, depressão ou para melhorar a performance, para adiar o envelhecimento. A construção e a modificação corporal, body building $^{l}$ e body modification ${ }^{2}$, estão cada vez mais presentes na pauta social. Isso porque o corpo é comunicação, vida e nosso meio de interatividade: é a nossa primeira mídia.

\section{CORPO, GESTALT, MÚSICA: vida em movimento.}

Consideramos o corpo humano um instrumento capaz de produzir e veicular musicalidade, já que a música é, comprovadamente, um significativo elemento de expressão e comunicação. Além disso, pode muito bem ser considerada como fator sociocultural, integrando o universo discursivo do mundo, influenciando e incorporando os valores humanos nos diferentes tempos e espaços. Sob a influência de uma mesma música, as pessoas se comunicam, independentemente do idioma, das ideologias políticas ou da diversidade das suas classes sociais.

É possível exemplificar o corpo como meio de comunicação musical através de uma breve viagem ao Rio de Janeiro do século XIX, para destacar o veículo que foi utilizado para a difusão da música, antes do advento do

\footnotetext{
${ }^{1} \mathrm{O}$ body building é um conceito peculiar e relativamente moderno: o corpo vivo como objeto público, termo que descreve a construção da massa muscular - desligada da ideia de força e de saúde pelo uso de pesos e exercícios com máquinas (GÓES In: VILLAÇA, GÓES, KOSOVSKI, 1999, 35).

${ }^{2} \mathrm{O}$ conceito de body modification traduz a prática baseada na tecnologia da cirurgia plástica, nas técnicas do piercing e da tatuagem, além da química dos esteroides. (GÓES In: VILLAÇA, GÓES, KOSOVSKI, 1999, 37).
} 
fonógrafo, em $1878^{3}$ : o assobio. Edinha Diniz explica que o assobio era tão frequente nas ruas do Rio de Janeiro que chamava a atenção dos visitantes estrangeiros.

Foi o principal "instrumento" da intercomunicação entre a música culta dos salões e teatros líricos e a música popular. Uma vez ouvida, mesmo da rua, pela gente simples, ele [o povo] encarregava-se de a disseminar e a adulterar (DINIZ, 1991, p.85).

Podemos, ainda, utilizar outro exemplo elucidativo e pertinente a essa temática. Raimundo Martins, em Música, percepção, expressão e conceito, nos lembra que a criança comunica-se através de movimentos, antes de desenvolver seu vocabulário. As habilidades para sincronização de movimentos corporais com estímulos rítmicos dependem mais dos fatores idade e maturação do que do fator de ensino (MARTINS, 1985, p. 19).

Essas informações precisam ser levadas em consideração no desenvolvimento da prática de Musicalização infantil. É o corpo em movimento, como prática comunicativa, inserido em um mundo repleto de experiências sensoriais. Ainda segundo Martins

Todo aprendizado musical deve surgir diretamente das experiências musicais imediatas, ou seja, experiências

\footnotetext{
${ }^{3}$ Do assobio ao advento do $\mathrm{CD}$ vieram várias conquistas. Foi em 11 de março de 1878 que o concessionário da patente do fonógrafo de Edison, Puskas, gravou perante a Academia de Ciências de Paris a frase "O fonógrafo tem a honra de ser apresentado à Academia de Ciências" e, em seguida, fez o cilindro girar repetindo essa frase. A veiculação musical dava um passo rumo à tecnologia que hoje conhecemos. Visando fins comerciais e educativos, os fonógrafos ganharam popularidade, em especial, como veículo de difusão musical.
}

relevantes que tenham $\mathrm{o}$ sabor da descoberta. Não há dúvida de que muito da hostilidade ao ensino de teoria vem do fato de que se ensina tal conteúdo através de verbalismos vazios, desvinculados de qualquer experiência e significância musicais (MARTINS, 1985, p. 32).

É possível fazer uma conexão entre o estudo do corpo como comunicação e a Gestalt?! Sim, se pensarmos a questão do corpo de uma forma global, inter e multidisciplinar. $\mathrm{O}$ corpo não é um meio por onde a informação simplesmente passa, pois toda informação que chega "entra em negociação com as que já estão”. O corpo é o resultado desses cruzamentos (...) "A mídia à qual o corpomídia se refere diz respeito ao processo evolutivo de selecionar informações que vão constituindo o corpo. A informação se transmite em processo de contaminação”. É o movimento ${ }^{4}$ que faz do corpo um corpomídia, defende Christiane (GREINER, 2005, p. 131).

“O corpo está em cena, sem que haja qualquer possibilidade de predizer o futuro e seus limites", salientam Fred Góes e Nilza Villaça (2000, p. 32). Além disso, "Não somos seres fragmentados; formamos um todo indissolúvel" (BERGE, 1988, p. 159).

\section{A Gestalt theory tem como} pressuposto que não se pode ter conhecimento do todo através das partes, mas das partes através do todo. Os conjuntos possuem leis

\footnotetext{
${ }^{4}$ Christiane Greiner explica que, embora o tema "movimento do corpo" tenha sido abordado em períodos anteriores, é a partir do início do século passado, especialmente com Delsarte, Dalcroze, Reil e Bonnier, que se desenvolve um interesse maior sobre a singularidade do corpo, do gesto, estados corporais, tendo em vista aplicações no campo de experimentações práticas na medicina e na arte $(2005$, p.62)
} 
próprias que regem seus elementos; por isso, só através da percepção da totalidade é que o cérebro pode, realmente, perceber, decodificar e assimilar um conceito (FIGUEIRÓ ${ }^{5}$ ).

\section{A Teoria da Gestalt estuda a} percepção e a sensação do movimento, bem como os processos psicológicos envolvidos diante de um estímulo e como este é percebido pelo sujeito. Encontramos evidências sobre a relação entre corpo e Gestalt utilizando como referencial teórico o trabalho da psicóloga e pesquisadora Monica Botelho, em Experiência estética $e$ corporeidade: fragmentos de um diálogo entre gestalt-terapia, arte e fenomenologia

A Gestalt-Terapia foi concebida por pensadores e clínicos que eram envolvidos em disciplinas artísticas: poesia, música e dança, teatro. Eles "encontraram nas artes uma visão de funcionamento ideal, a qual eles estenderam a toda atividade humana. Essa visão tornou-se a sua medida de saúde e doença e guiou sua prática em psicoterapia" (MILLER, 1980, p.87) ${ }^{67}$.

Parece-nos evidente a utilização da Gestalt como referencial para os estudos do corpo e os seus aspectos multidisciplinares. Há, entretanto, uma nova hipótese a ser investigada ainda neste trabalho. É possível a utilização dos postulados da Gestalt para

\footnotetext{
${ }^{5}$ http://pt.scribd.com/doc/11585091/Artigo-Gestalt

${ }^{6} \mathrm{http}$ ://pepsic.bvsalud.org/scielo.php?pid=S1808-

42812007000100012\&script=sci_arttext

${ }^{7}$ A Teoria da Gestalt se originou a partir de uma ramificação dos estudos sobre percepção realizados por Wertheimer, na Alemanha, em torno de 1920, inspirados no artigo seminal de Ehrenfels, intitulado Ueber Gestaltqualitäten, publicado em 1890. Essa teoria nasceu como uma reação ao pensamento psicológico da época, influenciado pela física do átomo, que considerava "os componentes da vida mental como sensações discretas, irredutíveis e homogêneas" (OSBORNE In: OLIVEIRA. Disponível em

http://www.seer.unirio.br/index.php/simpom/article/view/2444)
}

melhor planejamento de uma performance musical expressiva?

\section{CORPO, GESTALT E PERFORMANCE MUSICAL}

A performance musical é um evento único, que revela aspectos técnicos e emocionais; ao contrário da interpretação musical, que é construída, planejada durante o período de estudo, podendo ser reelaborada várias vezes, visando diferentes performances. Impossível, dessa forma, pensar em performance musical - seja o canto, a dança, a interpretação instrumental sem levarmos em consideração a questão corporal: essencial e reveladora. É importante que haja um viés cênico na interpretação.

Como não nos remetermos, por exemplo, ao compositor e pianista estadunidense Keith Jarrett? Suas técnicas de improvisação associam elementos do jazz a outros gêneros e estilos, como a música erudita, o blues, o gospel. E a performance?! Revela exatamente o corpo como elemento comunicativo, como mídia. Além disso, cada movimento interfere na execução, na produção sonora do pianista.

Além da genialidade de Keith Jarret, evidenciando nossa diferenciação entre interpretação e performance, escolhemos outros artistas que retratam bem nossa temática. O grupo Barbatuques - referência internacional em percussão corporal - revela bem o corpo na música e como instrumento 
musical. Os vídeos da pianista e compositora internacional Maria Alice de Mendonça ${ }^{8}$, Ph.D. em Performance Pianística pela UCLA - EUA, interagindo com um ator e uma bailarina, mostram o trabalho de corpo denotado na apresentação de cada um dos intérpretes.

Merece também destaque a performance da maestrina Lígia Amado, quando à frente da Orquestra Sinfônica Nacional (OSN/UFF). Fica perceptível que a regência é muito mais do que transmitir a um conjunto instrumental ou vocal o conteúdo rítmico e expressivo de uma obra musical através de gestos convencionais; a regência vai muito além do elo entre maestro, compositor e músicos.

Ao participarmos de um ato comunicativo, de uma interação social, usamos todo o nosso corpo, como abordamos na introdução deste trabalho. Outra referência importante para essa reflexão é Patch Adams, o amor é contagioso. Esse filme evidencia a relevância de métodos pouco convencionais como significativos complementos para as terapias tradicionais, sobretudo através do personagem Patch ${ }^{9}$, da utilização do humor, do entretenimento e das abordagens comunicacionais variadas e ricas em elementos simbólicos.
Outro aspecto importante do filme é que "Patch" coloca em risco a sua formação acadêmica e o seu futuro profissional ao desafiar a comunicação de conduta (regulada por fatores socioculturais) e "abusar" da cinésica (estudo do comportamento comunicativo do corpo) em seus atos comunicativos. Simples objetos, adereços, vestuários tornam-se importantíssimos para a composição do perfil do personagem que demonstra, do início ao final do filme, a riqueza da comunicabilidade corporal.

No que se refere à relação com a Gestalt, Álvaro Henrique explica, em $O$ Planejamento da Expressividade na Música Contemporânea, que a respeito da percepção sonora, da cognição humana e a resposta habitual de um ouvinte ideal, o trabalho dos psicólogos da Gestalt demonstra que a compreensão não é uma questão de perceber estímulos únicos, ou sons isolados, mas uma questão de agrupar estímulos em padrões e relacionar esses padrões uns com os outros (MEYER, 1956, p.6). Ainda segundo o autor:

a relação entre os padrões que nossa percepção agrupa cria expectativas, que têm o potencial de gerar emoção, e podem tornar uma interpretação musical expressiva. Ainda sobre os padrões de percepção da Gestalt, eles podem indicar quais expectativas são geradas, dessa forma a análise da partitura buscando reconhecer e identificar quais padrões estão presentes naquela composição aponta quais expectativas são geradas por aquela obra musical. ${ }^{10}$

\footnotetext{
${ }^{8}$ http://mariaalicepiano.blogspot.com.br/

${ }^{9}$ Hunter Doherty "Patch" Adams é um médico norte-americano, famoso por sua metodologia inusitada no tratamento a enfermos. Formado pela Virginia Medical University, também fundou o Instituto Gesundheit em 1971. Mais informações em http://www.patchadams.org/
} 
Quanto à performance artística, cabe apontar como sugestão a análise da obra musical a ser estudada e interpretada, segundo padrões de percepção da Gestalt que podem ser reconhecidos e trabalhados. Ainda em conformidade com Álvaro Henrique, ao executar a obra, é importante relacioná-los (os padrões da Gestalt):

(...) de forma a criar expectativas que serão inibidas, bloqueadas ou enfraquecidas para gerar incerteza, manipulando não quais eventos ocorrem, mas a forma como eles ocorrem". ${ }^{11}$

Dessa forma, chega-se a "ter uma interpretação musical expressiva para uma composição que não dispõe de uma partitura com informações suficientes para $o$ intérprete". Além disso, ressaltamos o quanto a Gestalt nos permite perceber "além" do registro na partitura.

\section{CONCLUSÃO}

Há muito o que se discutir sobre Gestalt e música. Este breve estudo nos possibilita, entretanto, apontar a estreita ligação entre corpo, movimento, música e Gestalt. Um brainstorm? Uma "colcha de retalhos"? Não! Este artigo é um produto híbrido, fruto do trabalho de uma pesquisadora apaixonada e que acaba por dar o testemunho da importância da Gestalt: o que é colocado diante dos olhos deve estar exposto ao olhar; é preciso ver além. O inteiro

$$
{ }^{11} I d \text {. }
$$

é interpretado de maneira diferente que a soma das suas partes.

Defendemos aqui também a relevância do estudo do corpo como elemento performático, como uma mídia, um elo entre o ser humano e o mundo que o cerca. Apontamos como o corpo construído, modificado é capaz de revelar, dar pistas que vão além da matéria - mas que informam também sobre o pensamento, a emoção e os costumes de determinado tempo e espaço, além de peculiaridades do ser humano. Mostramos o corpo como instrumento musical e o corpo na música, o quanto as dimensões físicas (motoras), emocionais, sensoriais, intelectuais são interligadas e compreensíveis, como um todo, através da Gestalt.

\section{BIBLIOGRAFIA}

*NIETZCHE. In: BERGE, Yvone. Viver o seu corpo. Por uma pedagogia do movimento. Trad. Estela dos Santos Abreu e Maria Eugênia de Freitas Costa. São Paulo: Martins Fontes, 1988.

Imagem: http://goo.gl/Q5u2eu

BEUTTENMÜLLER, Glorinha e LAPORT, Nelly. Expressão vocal e expressão corporal. Rio de Janeiro: Enelivros, 1992.

CHERRY, Colin. A comunicação humana. São Paulo: Cultrix, 1980.

DINIZ, Edinha. Chiquinha Gonzaga uma história de vida. Rio de Janeiro: Rosa dos Tempos, 1991.

GAYOTTO, Lucia Helena. Voz do ator: a partitura da ação. São Paulo: Plexus, 2002. 
GONÇALVES, M. H. B. Comunicação verbal e não-verbal. Rio de Janeiro: SENAC, 1996.

GREINER, Christine. O corpo. Pistas para estudos indisciplinares. São Paulo: Annablume, 2005.

PARRY, John. Psicologia da comunicação humana. Trad. Octavio Mendes Cajado. São Paulo: Cultrix, 1980.

QUINTEIRO, Euclosia Acuña. Manual de terapia corporal como base da estética da voz e da fala. Carapicuiba: Pró-Fono Departamento Editorial, 2000.

RECTOR, Mônica e TRINTA, Aluízio Ramos. Comunicação não verbal: a gestualidade brasileira. São Paulo: Vozes, 1990.

ROCHA, Maristela. Corpo: a primeira mídia. Apresentação (pôster) na $56^{\circ}$ Reunião Anual da SBPC, realizada de 17 a 22 de julho de 2005, na Universidade Estadual do Ceará, Fortaleza.

Corpo: a primeira mídia. Aspectos contemporâneos e multidisciplinares. Revista da Universidade Vale do Rio Verde, v. 11, p. 32, 2013.

Corpo e juventude em foco. Publicação online: www.reagente.com. 27.10.2008.

SANTAELLA, Lucia. Corpo e comunicação: sintonia da cultura. São Paulo: Paulus, 2004.

SILVA, Maria Júlia Paes. Comunicação tem remédio. A comunicação nas relações interpessoais em saúde. São Paulo: Loyola, 2006.

VILLAÇA, Nilza; GÓES, Fred; KOSOVSKI, Ester. Que corpo é esse? Novas perspectivas. São Paulo: Mauad, 2000.

\section{Bibliografia eletrônica}

ALVIM, Monica Botelho. Experiência Estética e corporeidade: fragmentos de um diálogo entre Gestalt-Terapia, Arte e Fenomenologia. Disponível em http://goo.gl/0dKpFW Acesso em 01.07.2013.

FALCON, Jorge A. Música fora dos limites: um estudo de algumas capacidades e limiares cognitivos humanos. Disponível em http://salavirtual.unincor.br/mod/resource/vie w.php?id=5550 Acesso em 01.07.2013

FIGUEIRÓ, Cristiano. Influência da Gestalt theory na pré-composição da peça "Canela-Gamboa". Disponível em http://pt.scribd.com/doc/11585091/ArtigoGestalt Acesso em 28.06.2013.

LEVITIN, Daniel. A Ilusão Musical. Disponível em http://goo.gl/Q8Feb. Acesso em 01.07.2013.

OLIVEIRA, Helder Alves. Aplicação de Princípios Gestálticos no Planejamento Composicional de Segmentos. Disponível em http://goo.gl/UaVNjS Acesso em 20.06.2013.

SANTOS, Alvaro Henrique Siqueira Campos. O planejamento da expressividade na música contemporânea. Disponível em http://repositorio.unb.br/handle/10482/12511 Acesso em 04.07.2013.

\section{Vídeos}

AMADO, Lígia (regência) In: VILLALOBOS. Choros no 10. Orquestra Sinfônica Nacional (OSN/UFF); Coral Brasil Ensemble. Disponível em http://goo.gl/A4CPI6 Acesso em 01.07.2013.

(regência) In: BRAGA, Francisco. A

Paz/O Cortejo. Orquestra Sinfônica Nacional (OSN/UFF). Coral Brasil Ensemble.

Disponível em http://goo.gl/1kDGbZ Acesso em 04.07.2013. 
BARBATUQUES. Cadeirada. Disponível em http://goo.gl/ulp4lV Acesso em 01.07.2013.

\section{JARRETT, Keith. Solo concert, Tokyo,} 1984. Disponível em

http://www.youtube.com/watch?v=KPgEoDt_ Duc Acesso em 01.07.2013.

MENDONÇA, Maria Alice de; AMARAL, Marcus. Sanga. Disponível em https://www.youtube.com/watch?v=A2Vrt11 4fdc Acesso em 01.07.2013.

MENDONÇA, Maria Alice de; MARQUES, Silvana. Dança do silêncio. Disponível em https://www.youtube.com/watch?v=_d8982ZI A9M Acesso em 01.07.2013.

SHADYAC, Tom. Patch Adams: o amor é contagioso. Título Original: Patch Adams. Gênero: Drama. Tempo de Duração: 114 minutos. Ano de Lançamento (EUA): 1998. Site Oficial: www.patchadams.com 